\title{
A Pediatria na Bahia: Martagão Gesteira (1884-1954) e a implementação de um campo científico, 1916-1937
}

\section{Virlene Cardoso Moreira ${ }^{1}$}

\begin{abstract}
Resumo
O processo de institucionalização da Pediatria na Bahia deu-se com a criação da cátedra na Faculdade de Medicina da Bahia. Todas as ações decisivas foram movidas pelos professores da disciplina na faculdade, criando instituições filantrópicas de assistência à saúde da infância, desenvolvendo pesquisa, divulgando conhecimento. É sobre a trajetória de um desses personagens que o presente artigo irá se debruçar. Martagão Gesteira, titular da 'Clínica Pediátrica e Higiene Infantil', fundador da Liga Bahiana Contra a Mortalidade Infantil e da Sociedade de Pediatria da Bahia, teve uma atuação importante no estado para consolidação da Pediatria enquanto campo científico.
\end{abstract}

\section{Palavras-chave}

História da Medicina; Pediatria; Filantropia

\begin{abstract}
Paediatrics' institutionalization process in the state of Bahia took place with the creation of the paediatrics' chair at the Bahia's School of Medicine. The professors of this discipline took all decisive actions at the faculty, by creating philanthropic institutions for child health care, researching, disclosing knowledge etc. This article will address the trajectory of one of these professors. Martagão Gesteira, holder of the Paediatric Clinic and Child Hygiene, founder of Bahian League Against Child Mortality, and the Bahia Paediatric Society, played an important role in order to consolidate paediatrics as a scientific field in the state.
\end{abstract}

\section{Keywords}

Medical History; Paediatrics; Philanthropy

\footnotetext{
${ }^{1}$ Instituto Federal da Bahia, Salvador, Bahia. $₫$ virnamoreira@yahoo.com.br.
} 
O processo de consolidação da pediatria como área médica especializada no Brasil se deveu à criação do curso livre de medicina infantil na Policlínica Geral do Rio de Janeiro por Carlos Arthur Moncorvo de Figueiredo (1846- 1901) em 1882. As ações de "Moncorvo Pai" ajudaram a abrir caminho para o surgimento da cátedra especial de pediatria nas faculdades de medicina do império, à época sediadas no Rio de Janeiro e em Salvador. ${ }^{2}$ No entanto, houve um longo caminho até que essas medidas resultassem na consolidação da pediatria como campo científico.

Este artigo pretende se debruçar sobre o percurso de conformação da pediatria enquanto campo científico no contexto baiano: da oferta da disciplina na Faculdade de Medicina na Bahia, em $1884,{ }^{3}$ até que de fato houvesse um ambiente de produção de conhecimento científico em medicina infantil foram quase três décadas. O professor Joaquim Martagão Gesteira (1884-1954)4 foi fundamental nesse processo. Titular da cátedra de Clínica Pediátrica e Higiene Infantil na instituição de ensino médico, trilhou uma carreira acadêmica e política responsável por conduzir uma geração de médicos que se dedicaram aos estudos das questões pertinentes à pediatria, culminando com a fundação da Sociedade de Pediatria da Bahia (SPB), em 1930.

As produções científicas de Martagão Gesteira, as teses de doutoramento dos estudantes sob sua influência acadêmica, os documentos da Liga Bahiana Contra Mortalidade Infantil, fundada pelo pediatra e professor em 1923, assim como as atas da SPB, foram fontes privilegiadas para analisar a dinâmica que resultou na consolidação da pediatria enquanto campo científico.

“Campo científico - sistema de relações objetivas entre posições adquiridas em lutas anteriores - é o lugar e o espaço de uma luta concorrencial. O que está em luta são os monopólios da autoridade científica (capacidade técnica e poder social) e da competência científica (capacidade de falar e agir legitimamente, isto é, de maneira autorizada e com autoridade) que são socialmente outorgadas a um agente determinado." ${ }^{5}$

O que subjaz ao conceito proposto por Pierre Bourdieu é a ideia de que a ciência, longe de ser um universo "puro" e desconectado com o exterior, é um campo social como

\footnotetext{
${ }^{2}$ Em 25 de fevereiro de 1882, Moncorvo de Figueiredo enviou ao governo provincial uma solicitação para que fosse criada uma cátedra de clínica infantil nas faculdades de medicina do país. Documento esse que respaldou a criação da 'Clínica de moléstias médicas e cirúrgicas de crianças", Lei 3.141, de 30 de outubro de 1882. (Arthur de Figueiredo Moncorvo Filho, Histórico da Protecção à Infancia no Brasil 1500-1922 [Rio Janeiro: Departamento da Criança/Empreza Grafica Editora, 1926.]).

${ }^{3}$ Até a criação da cátedra de pediatria, não havia em Salvador cursos livres, médicos ou instituições engajadas em ações nomeadamente voltadas para a medicina infantil. Em 1883, o professor de Clínica Médica, Frederico de Castro Rebello, ofereceu-se para reger interna e gratuitamente o ensino de pediatria na Faculdade de Medicina da Bahia. (Livro de Atas das Sessões da Congregação da Faculdade de Medicina da Bahia 1882-1888 - Sessão de 01 de março de 1883).

${ }^{4}$ Martagão Gesteira graduou-se pela Faculdade de Medicina da Bahia em 1908. Em 1911 foi assistente de Clínica Pediátrica Cirúrgica e Ortopedia, sob regência de Alfredo Ferreira Magalhães. No ano seguinte ingressou como livre docente de Clínica Pediátrica e Higiene Infantil. Em 1914, prestou concurso para titular da mesma cátedra, ali permanecendo até 1937, quando foi transferido para a Universidade do Brasil, no Rio de Janeiro.

${ }^{5}$ Pierre Bourdieu, “O Campo Científico," in A Sociologia de Pierre Bourdieu, org. Renato Ortiz (São Paulo: Olhos D’Água, 2003): 112.
} 
outro qualquer, com formas específicas de relações de força e monopólios, lutas e estratégias, interesses e lucros. O que torna o campo científico específico, na perspectiva do autor, é o que os concorrentes concordam sobre os princípios de verificação de determinada "realidade", a respeito dos métodos de validação de hipóteses e teses. Dito de outro modo, o que torna o campo científico singular é o consenso entre os pares/concorrentes sobre o contrato tácito, que é político e cognitivo, que funda e rege o "trabalho de objetivação". ${ }^{6}$

\section{Os estudos sobre a mortalidade infantil: a construção de um capital científico}

Em 1916, Martagão Gesteira publicou os resultados de uma década de pesquisas no Instituto de Proteção e Assistência à Infância da Bahia (IPAI). ${ }^{7}$ Na elaboração dos estudos, o professor reuniu dados a respeito das doenças mais recorrentes entre as crianças atendidas no instituto, distribuídas por faixa etária. Os dados o levaram a afirmar que o percentual de mortes em crianças com idade entre 0 e 2 anos era maior que em outras faixas etárias, e que as moléstias gastrointestinais lideravam as causas (34\%). A repercussão do trabalho foi significativa. Diferentemente de outros estudos que mencionavam a mortalidade infantil, Gesteira propunha uma relação direta entre a morte de lactentes em Salvador com as afecções digestivas, explicando sua etiologia e propondo soluções ao problema. ${ }^{8}$

Este concluiu que as causas das doenças digestivas nos lactentes originavam-se de erros dietéticos, sendo o maior vilão a dieta do leite artificial. O aleitamento artificial, e/ou outros em substituição ao aleitamento natural, conduzia à superalimentação ou subalimentação. Os dois fenômenos, ao contrário do que se poderia supor, não estariam relacionados necessariamente à condição social da família, uma vez que as mesmas afecções foram encontradas também nas crianças atendidas em sua clínica particular. Na perspectiva do pediatra, o desconhecimento das mães em relação à nutrição era responsável pelas perturbações gástricas advindas da alimentação. À luz de teorias alemãs sobre a patogenia das doenças digestivas, Gesteira apresentou como objetivo do estudo "chamar a atenção dos nossos clínicos para o subsidio trazido ao diagnóstico das dispepsias infantis pela prova alimentar de Finkelstein e os recentes processos de exame químico das fezes". ${ }^{9}$ Com isso, pretendia estudar o papel que essas afecções representavam na mortalidade infantil na Bahia, verificação que, a seu ver, àquela época ninguém ainda havia feito.

Ainda tomando por base os trabalhos de estudiosos alemães, Gesteira classificou os casos de gastroenterites observados no IPAI como dispepsias alimentares e orgânicas, acusando o predomínio da primeira. Por dispepsias alimentares entendia os lactentes cujo organismo reagia bem à amamentação artificial e cujas afeções advinham exclusivamente de erros alimentares. Já as dispepsias orgânicas referiam-se aos casos em que os lactentes não

\footnotetext{
${ }^{6}$ Bourdieu, Os usos da ciência: por uma sociologia clínica do campo científico (São Paulo: UNESP, 2004), 33.

${ }^{7}$ O Instituto de Proteção e Assistência à Infância da Bahia foi fundada em 1903 por professores de pediatria da Faculdade de Medicina da Bahia (Frederico de Castro Rebelo (1855-1928) e Alfredo Ferreira de Magalhães (18731943) Instituição filantrópica, tinha por objetivo prestar assistência às crianças pobres e doentes. Com a criação do dispensário para tratamento de doenças infantis em 1904, porém, o IPAI-BA foi se tornando um espaço médicodidático para as aulas de pediatria da FMB até a fundação da Liga Bahiana Contra Mortalidade Infantil, em 1923. ${ }^{8}$ Gesteira, “As afecções Digestivas no Instituto de P. e A. à Infância da Bahia," Gazeta Médica da Bahia 3 (jul. 1916).

${ }^{9}$ Ibid., 161.
} 
suportavam o leite de vaca, ainda que esse fosse ministrado convenientemente, por insuficiência de sucos digestivos, que poderia ter origem hereditária ou adquirida.

Os casos de subalimentação verificados por Gesteira eram majoritariamente provocados pelo uso de leite condensado em diluições extremas. ${ }^{10}$ Além dessas infrações quantitativas, havia outra de ordem qualitativa que consistia no emprego prematuro de substâncias alimentares impróprias à capacidade digestiva do lactante. $\mathrm{O}$ erro mais recorrente entre o público atendido no IPAI era o uso de papas na alimentação de recémnascidos. O emprego assíduo da farinha de mandioca tornava essa prática alimentar ainda mais problemática. Isso porque, além de feculenta, a riqueza em celulose, cujas fibras incapacitavam a digestão, constituía fonte abundante de resíduos irritantes para a mucosa digestiva do lactante.

Ainda em 1916, Gesteira divulgou sua pesquisa no Primeiro Congresso Americano da Criança, realizado em Buenos Aires, Argentina. Lidiane Ribeiro analisou as duas publicações, o artigo e a comunicação apresentada no Congresso como documentos importantes que marcam a especificidade da abordagem do pediatra em relação à mortalidade infantil. ${ }^{11}$ A partir das experiências no IPAI e no serviço médico didático do Hospital Santa Isabel ${ }^{12}$, cujos estudos apresentavam resultados próximos aos obtidos na instituição filantrópica ${ }^{13}$, além dos estudos franceses clássicos e recentes estudos alemães, empreendidos por Adalbert Czerny (1863-1941) e Heinrich Finkelstein (1865-1942), Gesteira desenvolveu nomenclaturas e classificações próprias para os problemas decorrentes da alimentação artificial na primeira infância.

Um suposto dilema franco-alemão estava em curso entre os pediatras do Brasil no que se refere à interpretação dos fenômenos da fisiologia nutritiva dos lactentes. Os autores franceses, classicamente referenciados no país, passaram a concorrer com os alemães a partir de meados da década de 1910 como suporte analítico às questões da especialidade pediátrica, sobretudo no quesito distúrbios alimentares. O pediatra Pedro de Alcântara (1901-1979), em 1929, escreveu um longo artigo sobre isso, analisando as obras dos principais nomes da pediatria francesa. Seu objetivo era mostrar que havia doutrinas interpretativas divergentes, mas que, a depender do aspecto, posições eram compartilhadas por estudiosos das duas nacionalidades, defendendo, assim, que não havia "escolas" francesa e alemã, até porque entre pediatras da mesma nacionalidade encontravam-se posições antagônicas. ${ }^{14}$ De todo modo, a ideia de que a "escola pediátrica francesa" e a

\footnotetext{
${ }^{10} \mathrm{O}$ pediatra Orlando V. Orlandi mostra que a discussão "seio materno versus mamadeira" permaneceu importante século XX adentro, ressaltando o peso que o interesse econômico das indústrias de gêneros alimentícios para bebês teve sobre a questão. (Orlando V. Orlandi, Teoria e Prática do Amor à Criança: introdução à Pediatria Social no Brasil [Rio de Janeiro: Jorge Zahar Editor, 1985.])

${ }^{11}$ Lidiane Monteiro Ribeiro, "Filantropia e assistência à saúde da infância na Bahia: a Liga Baiana Contra Mortalidade Infantil, 1923-1935" (dissertação de mestrado, Casa de Oswaldo Cruz - FIOCRUZ, 2011), 42-49.

${ }^{12}$ Localizado no bairro de Nazaré, o Hospital Santa Isabel atendeu as demandas acadêmicas da Faculdade de Medicina da Bahia até 1948, quando foi inaugurado o Hospital das Clínicas.

${ }^{13}$ Francisco de Carvalho Sanches, “O Paludismo na Infância. Bahia” (tese de doutoramento, Faculdade de Medicina da Bahia, 1918), 23.

14 Pedro de Alcântara. "As escolas alemã e francesa de pediatria, em face dos distúrbios alimentares da $1^{\text {a }}$ infância," Pediatria Prática 2 (mar. 1929).
} 
"escola pediátrica alemã" estavam em terrenos contraditórios era opinião corrente entre os pediatras brasileiros.

O primeiro ponto sobre o que as duas escolas pediátricas discordavam, defendia Gesteira, era no tocante à denominação sob que deveriam ser englobados os distúrbios digestivos dos lactentes. Contra as clássicas denominações - gastroenterites, perturbações digestivas, perturbações gastrointestinais - a escola alemã trouxe os termos distúrbios nutritivos ou distrofias. Gesteira disse não ter sido convencido, e certamente não o seria, da noção que orientava as denominações alemãs, segundo a qual as desordens gastrointestinais do lactente (Finkelstein só abriu exceção para as infecções intestinais específicas), começavam por um distúrbio da nutrição geral, secundariamente manifestado para o lado do intestino. ${ }^{15}$

Gesteira afirmava haver equívocos na denominação da escola pediátrica alemã em considerar as patologias gastrointestinais como resultantes de distúrbios alimentares. Para ele, os transtornos nutricionais sucediam os episódios gastrointestinais e não os provocavam, como sugeria a interpretação germânica. A alteração da nutrição se caracterizava no lactente por retardo no ganho de seu peso e desenvolvimento estrutural, logo, as enfermidades do lactente se traduziam por transtornos da nutrição, com ou sem participação da mucosa digestiva. Assim, seria um defeito dessa denominação confundir estados patológicos de caráter e significações tão diferentes. ${ }^{16}$ Desse modo, sob a rubrica geral de 'perturbações gastrointestinais' admitiu três ordens de distúrbios: dispepsias, toxinfecciosas e distrofias. Abaixo, o quadro proposto.

\footnotetext{
${ }^{15}$ Gesteira, “Perturbações gastrointestinais do lactente: ensaio de classificação,” Brasil Médico 16 (out. 1925).

${ }^{16}$ Ibid.
} 


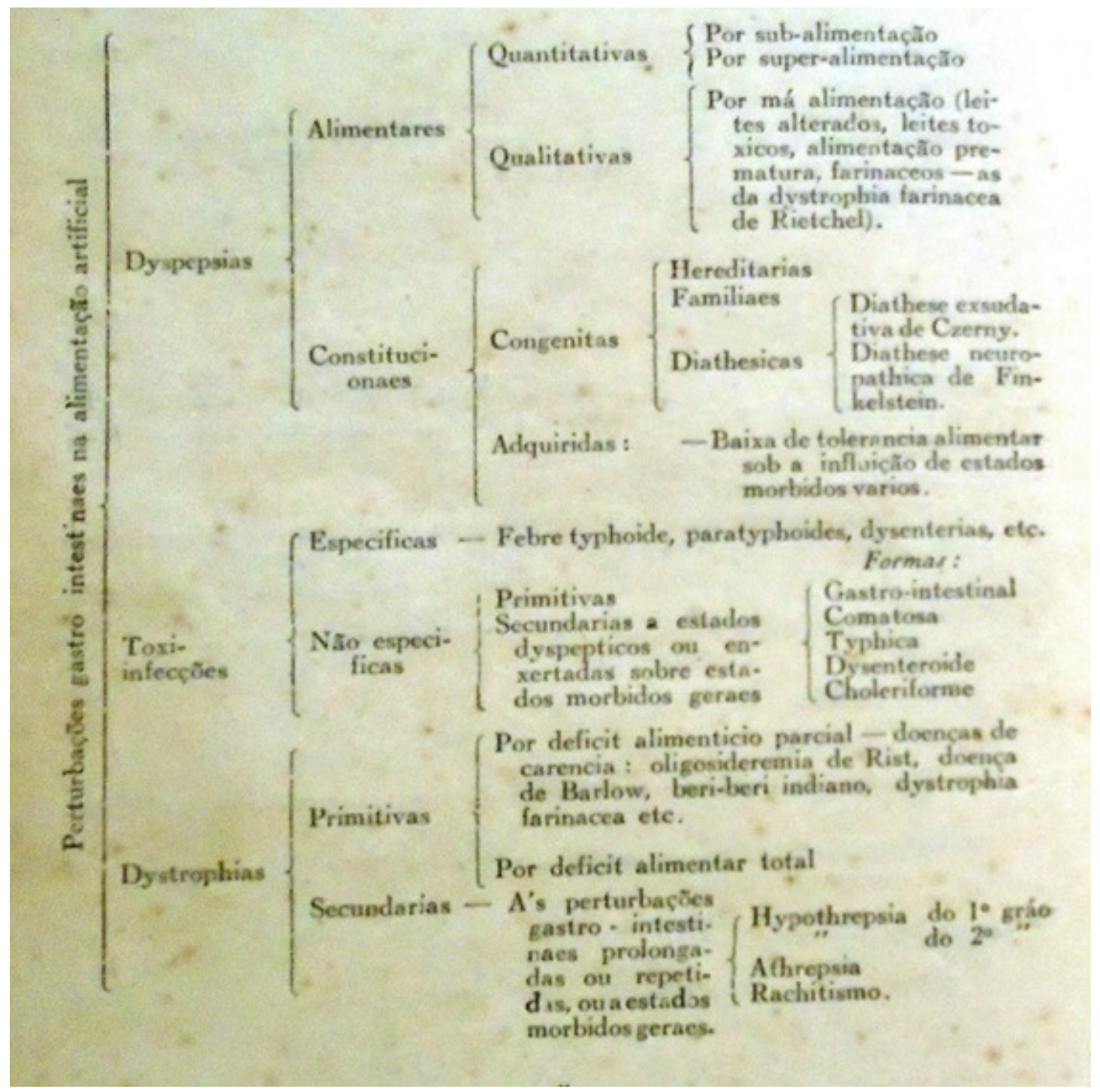

Organograma das perturbações gastrointestinais na alimentação artificial do lactente proposto por Martagão Gesteira. Fonte: Alcântara, Pedro. As escolas alemã e francesa de pediatria, em face dos distúrbios alimentares da

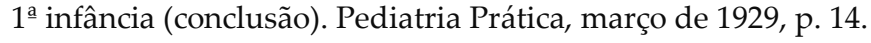

Nem sempre seria possível precisar onde acabava o distúrbio meramente funcional, provocado pelo alimento incompletamente digerido, e onde começava a ação toxicoinfecciosa, admitia Gesteira, uma vez que um episódio poderia ser consequência do outro. Por dispepsias, entendia os desarranjos simplesmente funcionais, sem fenômenos graves de intoxicação, providos da desproporção entre o alimento e o poder digestivo do trato gastrointestinais quer essa desproporção resultasse de defeitos quantitativos ou qualitativos do alimento, quer proviessem de deficiências fisiológicas do organismo do bebê. Daí a divisão em alimentares e constitucionais. ${ }^{17}$

Nas primeiras, o erro de regime podia residir na quantidade ou na qualidade do alimento ingerido - dispepsias quantitativas e qualitativas. As quantitativas podiam estar filiadas à insuficiência ou excesso de ração. No primeiro caso, tinha-se a dispepsia por subalimentação, correspondente ao quadro clínico: estacionamento ou decrescimento da

${ }^{17}$ Gesteira, “Perturbações gastrointestinais do lactente,” 221-223. 
curva ponderal, vômitos profusos e rebeldes, constipação ou, bem raras vezes, diarreia verde, a que se juntavam sinais de fome (sucção constante do dedo, voracidade no tomar a mamadeira, prantos após a mamadura) e aumento do fósforo urinário. Os elementos do quadro clínico, associados ao exame de urina e às indicações da anamnese, da balança e da prova alimentar, tornavam de fácil verificação essa modalidade de dispepsias. ${ }^{18}$

Não menos frequentes eram, todavia, os distúrbios por excesso de alimentação, apresentando-se de duas formas. Os fenômenos mórbidos que seguiam ao emprego dos alimentos impróprios à capacidade digestiva do lactente, denominada de dispepsias por má alimentação, em cujo grupo as distrofias farináceas se incluíam. Vindo em seguida o grupo das dispepsias constitucionais. Tal incapacidade por vezes era adquirida, resultante de abaixamento da tolerância alimentar sob a influência de diversos estados mórbidos, como o impaludismo, a gripe, o sarampo. Em outras situações, a deficiência da tolerância alimentar era herdada, sendo três as condições: estado congênito - erros no curso da gestação; estado congênito genético; e, por fim, incapacidade digestiva hereditária causada por problemas metabólicos. Não raro, porém, poderia um caso ser resultado de associação de fatores alimentares e constitucionais, resultando tipos de dispepsia mistas. ${ }^{19}$

Quanto às toxi-infecções, poderiam ser específicas e não específicas. As primeiras compreendiam a "febre tifica", a "colibacilose", as "desinterias" etc. As outras poderiam ser primitivas ou se enxertarem secundariamente sobre estados dispépticos anteriores ou sobre estados mórbidos gerais. Primitivas ou secundárias, as toxi-infecções se mostravam sob várias feições clínicas, das quais na Bahia as mais comuns eram, na ordem de frequência com que se deparavam: gastrointestinal simples, "disenteroide comatosa", "tifica" e "coleriforme". ${ }^{20}$

Por fim, as distrofias, consideradas por Martagão como estado mórbido originado de deficiências alimentares ou provenientes de afecções digestivas mais ou menos demoradas, nas quais a nota clínica dominante era alteração profunda da nutrição geral. Subdividiu-as em primitivas e secundárias. As primitivas tinham como causa um déficit alimentar, que não satisfazia todas as necessidades do organismo. Caso esse déficit fosse parcial, as distrofias assumiam feição clínica especial, dependendo da natureza da substância alimentar carente, como "anemia ferripriva" ou "oligosideremia de Rist", a "doença de Barlow", o "beribéri" (com restrições, pois não acreditava que o da Bahia tinha exclusivamente essa origem), a "distrofia farinácea" etc. Se a deficiência alimentar fosse total, o quadro clínico seria o da inanição, que poderia levar a criança a uma fraqueza geral do organismo. As distrofias secundárias, por sua vez, se originavam tanto de distúrbios gastrointestinais prolongados ou curtos em repetição, como de estados gerais mais ou menos graves e duradouros. Em qualquer dos casos, o aspecto clínico da distrofia seria ora, e mais raramente, o de raquitismo (que era mais próprio da segunda infância) ora o da atrofia infantil. ${ }^{21}$

\footnotetext{
${ }^{18}$ Gesteira, "Perturbações gastrointestinais do lactente," 221-223.

${ }^{19}$ Ibid.

${ }^{20}$ Ibid.

${ }^{21}$ Ibid.
} 
Pedro de Alcantara fez uma crítica à classificação de Gesteira, considerando-a mais híbrida que mista. Ao invés de materializar o critério etiológico e clínico pretendido, o crítico afirmou que o que o pediatra baiano conseguiu foi uma dupla classificação, sendo possível, desse modo, perceber um grupo de quadros clínicos e outro de causas segundo os quadros clínicos. Além de confusa, a classificação trazia o inconveniente da complexidade, opinou Pedro de Alcântara. Assim, certas afecções teriam dupla colocação do quadro, conforme fosse considerada, por sua etiologia ou seu aspecto clínico. ${ }^{22}$

Embora Gesteira dissesse que esse esforço de classificação das perturbações causadas em alimentação artificial fosse simplesmente um esboço de agrupamento para facilitar as aulas práticas de sua clínica pediátrica na faculdade de medicina, ele resulta de estudos cuidadosos e observações clínicas minuciosas, principalmente no IPAI, apontando para um interesse direcionado aos problemas da mortalidade infantil: doenças gastrointestinais e primeira infância. O pediatra estava construindo um lugar de especialista em doenças provocadas por alimentação artificial num público bem específico, a primeira infância.

O que se depreende nas produções de Gesteira nesse período, através de sua posição frente às questões científicas do seu tempo, é que ele estava agindo estrategicamente de modo a obter o reconhecimento de seus pares. Munia-se, assim, de um repertório que lhe possibilitaria somar o que Bourdieu definiu como capital científico, uma especificidade do capital simbólico. Considera-se, assim, que se trata de um momento em que o pediatra baiano dedicou-se em acumular esse capital. "Acumular capital é fazer um "nome" próprio, conhecido e reconhecido, marca que distingue imediatamente seu portador, arrancando-o como forma visível do fundo indiferenciado, despercebido e obscuro no qual se perde o homem comum". ${ }^{23}$ Desse cabedal, construiu em torno da cátedra de Clínica Pediátrica e Higiene Infantil da Faculdade de Medicina da Bahia uma ordem científica que foi muito importante para desenvolver uma agenda de pesquisa que lhe trouxe um respaldo, inclusive político, no cenário nacional.

\section{A Liga Bahiana Contra Mortalidade Infantil.}

Os diálogos desenvolvidos entre Gesteira e pediatras de outros centros do país tiveram repercussões políticas importantes, pois o colocou como interlocutor na Bahia para desenvolvimento de políticas públicas de assistência à infância. Em 1923, fundou a Liga Bahiana Contra Mortalidade Infantil (LBCMI), cuja finalidade era atacar o problema da mortalidade infantil. Em coerência aos estudos que vinha desenvolvendo, a LBCMI tinha como público a primeira infância (crianças entre 0 e 2 anos) e dada as razões das doenças gastrointestinais apontadas em suas pesquisas, norteou seus serviços nos preceitos da puericultura. Outro ponto forte foi a parceria entre a instituição filantrópica e o poder público.

Okezi T. Otovo estudou a relação estabelecida entre a LBCMI e o governo federal como uma ação basilar na construção do estado moderno brasileiro. Uma nova república que elegeu as políticas públicas de assistência à saúde como um corolário para a cidadania.

\footnotetext{
${ }^{22}$ Alcântara, "As escolas alemã e francesa de pediatria".

${ }^{23}$ Bourdieu, “O campo científico," 121-122.
} 
A autora denominou o projeto desenvolvido pela LBCMI como movimento maternalista baiano, uma vez que ações da instituição seguiam os princípios da puericultura. Dessa maneira, através do bem-estar materno e infantil, o maternalismo tinha como foco a família pobre, fazendo desta o centro do discurso político de construção da nação brasileira. Na perspectiva da autora, as políticas públicas de assistência à maternidade em âmbito nacional foram efetivadas a partir da instituição baiana e foram bem-sucedidas no sentido de ter promovido uma melhoria social na vida da mulher negra pós-abolição. Mesmo reconhecendo que essa melhoria não alterou o cenário de profundas desigualdades sociais e de enraizamento do modelo de sociedade patriarcal e conservadora, ainda é muito otimista o olhar da autora, pois generaliza os efeitos da atuação tanto da LBCMI quanto dos projetos públicos de assistência à maternidade e infância. ${ }^{24}$

Na reunião solene de fundação da LBCMI estava presente o chefe dos serviços de higiene federal na Bahia, Sebastião Barroso, que expôs sobre as verbas destinadas à profilaxia infantil e garantiu que a instituição filantrópica contaria com auxílio da união para seus empreendimentos. ${ }^{25} \mathrm{~A}$ parceria público-privada ali selada fazia parte de um contexto político mais amplo colocado em curso a partir da década de 1920, quando o governo federal assumiu a responsabilidade de questões médico-sociais há muito presentes na sociedade brasileira. Entre as prioridades estavam a lepra, as doenças venéreas (principalmente a sífilis), a tuberculose e a higiene infantil.

A Bahia foi o único estado em que o governo firmou um convênio com a união que tornou possível a efetivação de uma Seção de Higiene Infantil (1923). Essa ficou ligada aos Serviços de Saneamento e Profilaxia Rural e sua direção foi confiada a Martagão Gesteira. Ana Paula Vosne Martins ${ }^{26}$ creditou "à insistência" do professor e a relação de amizade entre ele e Fernandes Figueira (1902-1928) (Inspetor de Higiene Infantil, Rio de Janeiro) a instalação da Seção de Higiene Infantil na Bahia. Em entrevistas concedidas a jornais locais, Gesteira divulgou que foi convidado por Figueira a ser um representante na Bahia desse projeto político nacional. $\mathrm{O}$ fato é que só levou adiante a empreitada filantrópica por ter certeza que o empreendimento não ficaria à mercê de doações. As falas dele nesse sentido, e os documentos administrativos da LBCMI, levam-nos a concluir que a concepção do serviço filantrópico foi moldada para recepcionar os serviços de higiene infantil, que seguia um modelo nacional. A contrapartida seria a garantia de subsídio do Estado à sobrevivência da instituição, ainda que nos relatórios da inspetoria o diretor apontasse que os subsídios federais não eram suficientes e vinham com atraso, o que o obrigava a usar constantemente os recursos da instituição filantrópica na execução dos serviços da inspetoria de higiene federal na Bahia.

A primeira instalação da LBCMI a ser inaugurada foi o consultório de lactentes, um 'consultório modelar de higiene infantil'. Entre junho e outubro, matérias circularam nos jornais locais noticiando o andamento das obras e explicando à população a natureza do serviço tão anunciado. Em uma dessas matérias, Gesteira explicou didaticamente que as

\footnotetext{
${ }^{24}$ Okezi T Otovo, "To form a Strong and populous nation": race, motherhood, and the state in Republican Brazil" (tese de doutorado, Faculty of the Graduate School of Arts and Sciences of Georgetown University, 2009).

25 "A Liga Bahiana Contra Mortalidade Infantil" Jornal A Tarde, 18 de junho de 1923.

${ }^{26}$ Ana Paula Vosne Martins, "Entre a benemerência e as políticas públicas: a atuação da Liga Bahiana Contra a Mortalidade Infantil no começo do século XX," Gênero 1 (2º Sem. 2005): 43-60.
} 
pessoas não esperassem da LBCMI algo parecido com atendimento hospitalar, pois se tratava de um consultório dedicado aos cuidados profiláticos infantis, sendo o alvo, portanto, as crianças sãs. Mas, diante do quadro grave de mortalidade infantil vigente e da insuficiência de serviços hospitalares na cidade, os profissionais da instituição não deixariam de prestar atendimento clínico às crianças de 0 a 2 anos que os procurassem. Assim, no consultório de lactentes as mães deveriam buscar conselhos profiláticos, principalmente relativos à boa nutrição.

As funções do consultório não deveriam ser confundidas:

“[...] não é uma policlínica de crianças, nem tão pouco um ambulatório infantil comum, porém um instituto de puericultura e de preservação da saúde dos pequeninos, e recebendo crianças sadias e enfermas, particularmente de danos de alimentação e transtornos digestivos, faz obra de prevenção e de assistência, mas visa sempre fins profiláticos, pois com boas práticas puericolas e os preceitos solícitos de uma boa higiene alimentar, de uma salutar dietoterapia, dissipa muitas desordens digestivas, remove múltiplos transtornos nutritivos e previne numerosas moléstias graves, que na idade da lactancia são causa anormal da mortalidade." 27

O relatório técnico dos serviços da Inspetoria Federal de Higiene Infantil na Bahia para o ano de 1925, produzido por Gesteira, aponta que o objetivo da inspetoria infantil e da LBCMI de dedicar-se exclusivamente a obras de puericultura não foi alcançado. Além dos consultórios de lactentes, foram ofertados à comunidade carente de Salvador atendimentos clínicos em dispensários infantis desde o ano seguinte à fundação das instituições, com ampliação da faixa etária para pré-escolares e escolares. Em menos de um ano, Salvador já contava com três consultórios/dispensários dos serviços da parceria entre a instituição filantrópica e a inspetoria de higiene: Regina Helena (só de lactentes), Adriano Gordilho (lactente e pré-escolares) e no Hospital Santa Isabel (lactente e pré-escolares). ${ }^{28} \mathrm{O}$ pediatra explicou tal decisão:

“[...] ao estabelecer o primeiro consultório de lactentes na Bahia, foi meu propósito dar-lhe um fim quase exclusivamente profilático, fazendo-o simples consultório de higiene infantil. Mas logo verifiquei a inteira impossibilidade de manter, num meio como o nosso, consultórios exclusivamente profiláticos: a mentalidade do nosso povo, para tanto ainda não preparada, por uma campanha prévia, não lograva compreender consultórios que a doentes não consultassem [...] reinava até, arraigado no espírito popular, o preconceito de que a criança que se pesa, "pasma", na expressão das comadres, isto é, não cresce nem engorda. Às solicitações insistentes das visitadoras para que fossem os pequenos ao

\footnotetext{
${ }^{27}$ Clemente Ferreira, “Consultórios de lactentes," Pediatria e Puericultura 3 (mar. 1932): 172.

${ }^{28}$ Gesteira, "Os serviços oficiais de Higiene Infantil na Bahia" (relatório apresentado ao 4º Congresso Americano da Criança, 1924), 1-2. (APEB/Fundo Secretaria de Educação e Saúde/ Série - Os trabalhos da Inspetoria de Higiene Infantil/Caixa 4084/Maço 117).
} 
consultório, antes de adoecerem, a resposta era invariável: "o meu filho esta bom, não precisa de médico, quando adoecer levarei $[\ldots]^{\prime 29}$

Entendia que a população soteropolitana não estava preparada para uma medicina profilática, o que fazia do atendimento médico curativo um aliado no processo de consolidação da puericultura. Outra razão, explicou, relacionava-se à escassez de espaços de cura em pediatria. A despeito dos objetivos do serviço federal de higiene infantil, Salvador apresentava uma realidade que tornava impossível a não transformação dos consultórios em dispensários infantis.

Em 1930, a LBCMI apresentou à Mesa da Santa Casa de Misericórdia da Bahia uma proposta de remodelação do asilo, o que gerou um convênio entre as duas instituições em de março daquele ano. Apesar da Santa Casa não concordar com a supressão da Roda dos Expostos, acatou mudanças que introduziram a perspectiva da ciência médica no tratamento das crianças sob sua tutela. Duas foram de extrema importância para criação de um novo espaço para o ensino da pediatria: corpo médico permanente, composto pelos pediatras da LBCMI, e a implantação da policlínica 'Arnaldo Baptista Marques', inaugurada em novembro do mesmo ano. ${ }^{30}$

Ocupando um pavilhão em terreno do Asilo dos Expostos, a policlínica infantil contava com sala de espera e matrícula, gabinetes de clínica médica e cirúrgica, oftalmológico e otorrinolaringologia, odontologia e fisioterapia, além de laboratório e sala de raio $x$. Esse espaço atendia crianças externas ao asilo (possuía estrutura médica própria, também sob os cuidados da LBCMI), e os recursos materiais disponíveis possibilitou que o ensino pediátrico da Faculdade de Medicina da Bahia fosse para ali transferido. Para atender a cátedra de pediatria, a policlínica contou também com salas de aula, gabinetes para internos e docentes e uma pequena biblioteca especializada. ${ }^{31}$

A instalação da policlínica 'Arnaldo Baptista Marques' concretizou os anseios de Gesteira em ter um espaço médico-didático próprio para a clínica pediátrica. Nesse espaço de assistência, exercício profissional, ensino e pesquisa - o professor e sua equipe de assistentes e internos desenvolveram as investigações que serão discutidas adiante, assim como fundaram a SPB.

\section{A Clínica Pediátrica e Higiene Infantil e sua agenda científica}

Com os trabalhos desenvolvidos por Gesteira, a clínica pediátrica foi ocupando cada vez mais espaço. O professor criou uma agenda científica, articulada com as discussões do seu tempo, e envolvia os estudantes da cátedra formando uma equipe de pesquisa, cujos resultados, em alguma medida, eram compartilhados academicamente. Os distúrbios digestivos começaram a compor os interesses do professor desde o início da carreira, conforme visto, e com o passar dos anos ele foi se especializando em fisiopatologia nutritiva do lactente.

\footnotetext{
${ }^{29}$ Sebastião Barroso, “A higiene infantil na Bahia uma lição de coisas,” Brasil Médico (nov. 1928): 1244.

30 Ribeiro, "Filantropia e assistência à saúde da infância na Bahia," 95-96.

${ }^{31}$ Ibid., 97.
} 
Nas décadas de 1920 e 1930 a fisiopatologia nutritiva do lactente tornou-se central na pediatria, derivando diversos temas de estudos. O primeiro ponto a considerar é a supremacia da atenção dada à primeira infância (0 a 2 anos). Esse período da vida era entendido como de extrema delicadeza, sobretudo os seis primeiros meses, pois desde o nascimento a criança se apresentava em iminência mórbida, pois vinham fracas ao mundo, sendo facilmente assaltadas por germes, que em pouco tempo atacariam o tubo intestinal. Abaixo a descrição da fragilidade do corpo do lactente nas palavras de Fernandes Figueira.

“O recém-nascido nasce miopragico, para que assim o digamos, e sem o auxílio dos circunstantes não poderia, ao contrário de outros animais, subsistir sob as influências do ambiente. Traz muita água nos tecidos e, portanto, precária defesa contra os germes; os órgãos funcionam requerendo excesso de assimilação, e entanto um só alimento é apropriado ao grácil aparelho gastroentérico; a termolabilidade torna temerosas as oscilações do frio e do calor; a pele delicadíssima facilmente se escoria abrindo passagem aos micróbios; o traumatismo, já por ocasião do parto, pode emprestar ao feto caracteres de inferioridade com que ele aporte à vida comum. Transpondo o canal útero vulvar, o gonococo assaltará a conjuntiva; coli e outros germes do intestino materno, estreptococos e estaphylococos do meio, do líquido amnico, desafiarão o irrisório revestimento da pele, e infecções oferecerão perigos ao mofino lutador. Para superá-las o sangue pouco disporá de naturais defesas até aos dois meses de idade, e ainda após, o organismo apresentará muitas vezes campo aberto à difusão septicemia. Essa a peculiaridade máxima da patologia infantil. [...] Manifesta-se o meio dificultando ou favorecendo o trabalho de adaptação. Reage o lactante à alimentação contra natureza, e tanto menos a tolera, quanto menos robustez possui ou vive em meio infeccionado." 32

Entender o funcionamento desse organismo em sua relação com a (des)nutrição foi direcionando o rumo das investigações que buscavam combater a mortalidade infantil. Permanecia o argumento de que a criança alimentada ao seio corria menos risco de morte em relação às alimentadas artificialmente, mas os alimentos artificiais poderiam apresentar bons resultados caso administrados adequadamente. Os problemas apontados pelo alimento artificial foram ganhando novas elaborações, a exemplo da composição inadequada para a idade e natureza da criança, qualidade dos componentes, contaminação por germes causadores de doenças, diferença de natureza entre o leite animal e os tecidos do organismo da criança e ausência de substâncias ativas (fermentos, vitaminas e substâncias imunizadas) destruídas pela fervura. Um outro elemento passou também a compor o repertório pediátrico mais acentuadamente, a questão da alimentação insuficiente, mas com a rubrica 'fome'. A fome, como causadora de diminuição da resistência aos agravos de toda natureza, se apresentava como um fator de mortalidade nos idos da década de $1930 .{ }^{33}$

Percorrendo as revistas especializadas em pediatria no período, Pediatria Prática (SP), Pediatria e Puericultura (BA) e Jornal de Pediatria (RJ), encontra-se diversos artigos com

\footnotetext{
${ }^{32}$ Fernandes Figueira, Elementos de patologia e higiene infantis (Rio de Janeiro: F. Briguet \& Cia. Editores, 1929), XIIXIII.

${ }^{33}$ Pedro de Alcântara, “Causas da Mortalidade Infantil,” Pediatria Prática 2 (dez. 1934).
} 
temáticas relacionadas à nutrição e vitaminas, estas no desenvolvimento de lactentes, estudo do cálcio, metabolismos, carências alimentares de modo geral. Os estudos em pediatria no ocidente caminhavam para a mensuração das necessidades alimentares de uma criança saudável. Em dezembro de 1936, por exemplo, foi realizado um encontro em Genebra (Organização de Higiene da Sociedade das Nações) com o objetivo de realizar um estudo das questões enviadas por diversos países a respeito das necessidades alimentares no primeiro ano de vida. Sem desconsiderar aspectos individuais da criança, a comissão estabeleceu parâmetros para calorias, proteínas, hidratos de carbono, gorduras e sais minerais, assim como recomendou o período mínimo de seis meses para alimentação exclusivamente ao seio. ${ }^{34}$

As teses defendidas no âmbito da cátedra de clínica pediátrica da Faculdade de Medicina da Bahia entre 1921 e 1932 refletem bem esse cenário. Foram 33 teses em um período em que essa já não era mais atividade acadêmica obrigatória, o que pode sugerir a importância que a disciplina ocupava institucionalmente. $78 \%$ desses estudantes foram internos da cátedra e elaboraram seus estudos sob indicação temática ou orientação de Gesteira.

Com essas pesquisas, Gesteira foi aumentando seu capital científico "puro" e institucional (participação em comissões, bancas, colóquios, cerimônias, reuniões etc.). $\mathrm{O}$ professor passou a representar a pediatria no estado e a faculdade de medicina em diversos eventos científicos no país e internacionalmente. Lembre-se, ainda, das conquistas alcançadas por ele em relação às instalações para o ensino da pediatria num momento em que as queixas sobre a precariedade da prática em diversas clínicas eram abundantes. Bourdieu assevera que o acúmulo dessas duas espécies de capital científico é "extremamente difícil". Ele conclui pela quase incompatibilidade de se manter esses dois capitais no mesmo patamar: "tendo, num extremo, os detentores de um forte crédito específico [científico "puro"] e de um frágil peso político e, no extremo oposto, os detentores de um forte peso político e de um frágil crédito científico". ${ }^{35}$ Para Gesteira, porém, isso não se mostrou um problema.

Uma das questões que o pediatra direcionou em seu "programa de pesquisa" foi a exploração do funcionamento do fígado da criança a partir de dois contextos hemoclasia (Lauro Almeida Passos, 1921) desnutrição (Hosannah de Oliveira, 1927). O fígado é um órgão de extrema importância no processo digestivo, pois, além de segregar a bílis (substância que auxilia na absorção de gorduras), executa múltiplas funções no metabolismo. A necessidade de estudar a fisiologia do fígado em crianças dava-se ao protagonismo das doenças relacionadas à nutrição. Mapear o funcionamento do órgão tornava-se importante para diagnóstico e tratamento. Para Lauro Almeida Passos, sugeriu investigações para verificar em crianças os resultados que o cientista francês Fernand Widal (1862-1929) encontrou no adulto quanto ao valor da hemoclasia para a exploração funcional

\footnotetext{
${ }^{34}$ Adauto de Rezende "As necessidades alimentares no primeiro ano de vida," Jornal de Pediatria 7 (jul. 1937).

${ }^{35}$ Bourdieu, Os usos da ciência, 38.
} 
do fígado. ${ }^{36}$ Gesteira indicou a Hosannah de Oliveira (1902-1994) o estudo do fígado na desnutrição infantil. ${ }^{37}$

O ponto de partida de Lauro Passos foi estudar as experiências lideradas por Vidal desde 1913. A investigação funcional do fígado em crianças surgiu como pauta científica após uma viagem que Gesteira fez à Europa, onde acompanhou pessoalmente as experiências de Fernand Vidal. Ao retornar, propôs a Lauro Passos que aplicasse em crianças as experiências feitas por Vidal em adultos para verificar se a exploração funcional correspondia. Gesteira ensinou o método ao estudante, mas não o colocou em contato com o resultado das pesquisas de Vidal, para "maior isenção de espírito, no apreciar os fenômenos", justificou. O interno realizou as investigações em crianças do serviço clínico do professor (Hospital Santa Isabel), se limitando a pesquisar a hemoclasia digestiva por meio da leucopenia (contagem dos leucócitos no sangue) e da variação da pressão arterial, sendo que a primeira prova foi decisiva às conclusões. Tomou um grupo de sete crianças, sendo três em crianças de fígado normal, três em doentes com lesão conhecida no fígado e outra com vulvo-vaginite. ${ }^{38}$

Os dados apresentados corroboraram a teoria de Fernand Vidal aplicada ao corpo infantil, qual seja, a de que era possível por hemoclasia digestiva, e somente até por prova de contagem de leucócitos, detectar anormalidade nas funções do fígado. Gesteira apresentou à Sociedade Médica dos Hospitais da Bahia, em sessão de 12 de junho de 1921, o resultado dessa pesquisa orientada por ele. Quando Lauro Passos apresentou a tese, a pesquisa já tinha sido apresentada em comunicação científica pelo professor. Após a comunicação, um médico fez ligeiras interrogações sobre a tensão arterial, o que o mestre explicou que as provas de Vidal indicavam que a tensão variaria de acordo com o tempo de afastamento da refeição, e que seu orientando só aferiu a tensão uma vez, falha que seria corrigida em outras investigações. Lauro Passos, no texto da tese, explicou que não conseguiu aferir a pressão tal indicado por Vidal por ter que lidar com todo o processo sozinho, ficando preso à prova da leucopenia, mas garantiu que isso não comprometeu os resultados.

Pelo plano de pesquisa, essa incursão seria a primeira parte do estudo. Outras duas se seguiriam: o estabelecimento da dose do leite necessária à prática da prova nas várias idades e o estudo do choque "hemoclasico" nos lactentes, nas quais deveriam apurar os efeitos produzidos pela albumina do leite humano e do leite de vaca, ingeridos e administrados por via subcutânea, sobre o equilíbrio leucocitário. Lauro Passos reconhecia que o último ponto seria sua verdadeira contribuição científica, pois nenhuma verificação nesse sentido havia sido feita até aquele momento. Algum tempo depois, porém, foram divulgadas pesquisas internacionais que verificavam esse fenômeno, mas os resultados estavam longe de ser conclusivos. De qualquer forma, o tempo não permitiria pesquisa tão complexa, asseverou o doutorando.

\footnotetext{
${ }^{36}$ Lauro Almeida de Passos, "A hemoclasia digestiva na exploração funcional do fígado" (tese de doutoramento, Faculdade de Medicina da Bahia, 1921).

${ }^{37}$ Hosannah de Oliveira, O fígado na hipotrepsia (tese de doutoramento, Faculdade de Medicina da Bahia, 1927).

38 Passos, A hemoclasia digestiva na exploração funcional do fígado.
} 
Gesteira estava buscando um elemento inovador no rol de problemas considerados importantes. Uma descoberta, que além de contribuir para o progresso da ciência, certamente traria um lucro simbólico importante. Ao divulgar o resultado da pesquisa antes da defesa da tese de Lauro Passos, o professor pretendia trazer a si a inovação, incorrendo na disputa pelo monopólio da autoridade científica, estratégia marcante no campo científico.

Hosannah de Oliveira defendeu sua tese em 1927. Antes de apresentar suas experiências e consequentes conclusões, chamou a atenção para as particularidades fisiológicas do fígado na vida intrauterina e durante a infância: a função biligênica e canalizador do ferro materno, e maior atividade da função glicogênica, respectivamente. As afecções do fígado na criança, diferentemente do que acontecia com o adulto, estariam em grande medida relacionadas ao fator congênito, afirmou o autor. A explicação era que o fígado recebia durante a vida uterina muita influência do organismo materno, que se doente, portador de uma "toxinfecção", transmitiria à futura criança vírus e toxinas, o que poderia ter uma ação patogênica. ${ }^{39}$ Para realizar os estudos fisiológicos do fígado em criança com desnutrição, Hosannah de Oliveira utilizou métodos já em curso, todos, segundo ele, passíveis de críticas. Além disso, a dificuldade na investigação ampliava-se em função dos problemas colocados pelas crianças em muitos procedimentos médicos. Seria possível detectar a normalidade ou não do funcionamento do fígado por meio de aspectos diferentes.

O processo de pesquisa sobre a funcionalidade do fígado posto em curso por Hosannah de Oliveira foi aparentemente mais tranquilo, definiu os métodos de investigação sem grandes problemas. $\mathrm{O}$ fato de ele não tecer qualquer debate sobre as provas escolhidas sugere que se tratava de métodos conhecidos e consolidados no meio acadêmico. O público pesquisado foram crianças na primeira infância (0 a 2 anos) diagnosticadas com desnutrição, dos serviços clínicos do Hospital Santa Isabel e da LBCMI. O objetivo era garantir "provas cabais que [permitissem], cientificamente, afirmar ou garantir [a] suposição" de que o fígado, tal outros órgãos secretórios, teria sua função orgânica comprometida em casos de desnutrição adiantada, já que na hipotrepsia, em geral, as glândulas endócrinas apresentavam-se com sua secreção diminuída.

O graduando seguiu a orientação do pediatra francês Antonie Marfan (1858-1942) de que era possível conhecer o funcionamento do fígado nas moléstias da digestão e da nutrição na primeira infância a partir da pesquisa da glicosuria alimentar e da glicuronoria, e também pela dosagem da ureia na urina, pelo estudo da leucocitose digestiva, pela pesquisa dos pigmentos biliares e dos seus derivados nas fezes. Das crianças que atendiam os critérios de sua pesquisa, conseguiu concluir todas as investigações em apenas doze. Realizou os exames funcionais de urina e fezes (exames macroscópico e químico), além das provas experimentais (glicosuria alimentar, levulosuria alimentar e glicuronuria provocada).

No mesmo ano que Hosannah de Oliveira realizava sua pesquisa, o colega de turma (e também interno dos serviços clínicos do professor Gesteira) Manoel Guimarães Correia investigava a ação da insulina, do extrato tireóideo e do sangue materno como medicamento no processo terapêutico da atrepsia (falta de nutrição). Esse estudo derivou de uma temática

${ }^{39}$ Oliveira, O fígado na hipotrepsia, 11-13. 
indicada por Martagão, que tinha por objetivo investigar a ação do extrato tireoides no processo terapêutico da atrepsia, testando os experimentos do pediatra francês Pierre Nobécourt (1871-1943). Manoel Guimarães, fazendo uma adaptação ao proposto por Jules Comby (1853-1947), assim a definiu:

“A atrepsia é uma síndrome de desnutrição geral, própria dos recém-nascidos e dos lactentes, começando na maioria das vezes por perturbações digestivas e terminando, mais ou menos, rapidamente por um emagrecimento profundo que dá à criança uma fácies engilhada, absolutamente característica." 40

Em crianças, a fase inicial da desnutrição era identificada por fenômenos de intolerância à absorção e assimilação das gorduras e hidratos de carbono contidos na alimentação. A evolução da desnutrição era acompanhada pelo peso do corpo, determinando o coeficiente da perda de peso, sendo este a relação existente entre o peso apresentado e o que deveria apresentar a criança caso o seu desenvolvimento tivesse prosseguindo normalmente. A desnutrição apresentava-se em níveis de gravidade, e diferentes deveriam ser as nomenclaturas definidoras. Foram as utilizadas entre os pediatras baianos no período: hipoatrepsia ( $1^{\mathrm{o}}$ e $2^{\mathrm{o}}$ graus) e atrepsia ( $3^{\mathrm{o}}$ grau), que seria o grau de decadência orgânica no lactente.

O foco de investigação de Manoel Guimarães relacionou-se, conforme visto, à terapêutica. Decidiu-se por observar a ação de três técnicas no combate à desnutrição: "homohemoterapia", extrato de tireóideo e insulina, todos processos injetáveis. Essas substâncias deveriam ser administradas em paralelo a uma dieta nutricional específica, funcionando como um acelerador ao restabelecimento orgânico da criança, já em estágio mórbido. Para chegar à conclusão de que a insulina era a opção mais eficaz, utilizou também registros feitos por ele e professores assistentes nos serviços de clínica pediátrica médica (Hospital Santa Isabel e LBCMI) entre 1925 e 1927.

As três opções de tratamento representariam o que havia de mais moderno na terapêutica da desnutrição. A "homohemoterapia" consistia na injeção de sangue materno na criança, cujos componentes se assemelhavam aos encontrados no leite humano. O sangue materno exerceria ação benéfica, pois, além das substâncias nutritivas presentes, provocaria uma reativação geral em todo funcionamento do organismo. Assim, a administração do sangue substituiria satisfatoriamente o leite materno que, conforme colocado pelo autor, era mais difícil de conseguir. O extrato da glândula tireóidea, por sua vez, agiria equilibrando o metabolismo da água, que desempenhava um papel importante nos estados de desnutrição infantil. Admitia-se que esse extrato exercia uma ação estimulante sobre a glândula vascular sanguínea, diminuída em seu funcionamento por consequência da desnutrição geral. A glândula tireoide, por presidir os fenômenos da nutrição, sofria alterações em seus aspectos histológicos e fisiológicos. ${ }^{41}$

\footnotetext{
${ }^{40}$ Manoel Guimarães Correia, “Considerações sobre a atrepsia e seu tratamento" (tese de doutoramento, Faculdade de Medicina da Bahia, 1927), 2.

${ }^{41}$ Correia, Considerações sobre a atrepsia e seu tratamento, 61-64.
} 
Originalmente, a insulina compunha o repertório de tratamento de diabéticos, mas quando se passou a notar o ganho de peso adquirido pelos doentes, pediatras dos Estados Unidos começaram (a partir de 1923) a experimentar a insulina em casos de hipoatrepsia e atrepsia. O doutorando Manoel Guimarães afirmou que a primeira pessoa a realizar essas pesquisas no Brasil foi Edécio Cunha, em 1926. Edécio Cunha era de Recife e estudava medicina na Bahia, e tal qual os outros aqui abordados, sua questão de pesquisa foi indicação do professor Gesteira. Sua tese foi publicada com o título 'A insulina na desnutrição infantil', em $1926 .{ }^{42}$

A tese de Edécio Cunha foi a principal referência utilizada por Manoel Guimarães para defender o uso da insulina na desnutrição infantil. Assim, concordava que a insulina agiria "como um hormônio pancreático, despertando as funções que estavam de há muito tempo adormecidas e isto porque a continuação da curva ponderal não cessa, depois de suspenso o emprego da insulina" ${ }^{\prime 3}$. Como a desnutrição se relacionava à diminuição ou ausência do poder de absorção, a insulina, que agia sobre o metabolismo tornando os hidratos de carbono e das gorduras assimiláveis, favorecia a absorção. ${ }^{44}$

Os textos de Manoel Guimarães e Edécio Cunha estão muito marcados por expressões que denotam a necessidade de divulgar o ineditismo da pesquisa. As comunicações de Gesteira a respeito, além de corroborar com essa demarcação, reforça, insistentemente, seu protagonismo, monopolizando, assim, a competência científica dentro do campo. Pode-se pensar esse ato, também, como estratégia de conservação desse mesmo campo, na medida em que impede que outro agente se transforme em concorrente, ou um subversivo, o que colocaria em risco a estrutura da distribuição do capital cientifico.

Edécio Cunha informava que muitos países (Brasil, França, Inglaterra, Itália) já seguiam os Estados Unidos no uso da insulina no tratamento da desnutrição. Para o Brasil, mencionou que o Laboratório de Biologia Clínica do Rio de Janeiro fornecia a substância em solução aquosa e preparada seguindo o método dos Estados Unidos, e foi desse laboratório que o serviço clínico de Gesteira comprou a substância.

A insulinoterapia consistia em injeções de insulina por via subcutânea e, logo após, o emprego a solução de glicose a $15 \%$, também por via subcutânea. Esse método era o recomendado genericamente. Edécio Cunha fez uma adaptação técnica, retirando a injeção de glicose e mantendo o regime alimentar que a criança estava submetida no hospital. Antes de iniciar a terapia, as crianças passavam por um controle de peso por duas semanas, só usando a insulina se o peso estagnasse ou diminuísse, caso contrário, continuava com o regime alimentar. Quando necessário, as injeções eram ministradas cotidianamente, na proporção de duas por quilo de peso da criança, meia hora antes da refeição. Não justificou a razão de dispensar a glicose, mas implicitamente podemos atribuir à escolha de protagonizar o uso de dieta alimentar no tratamento da desnutrição. Observou quatro crianças dos serviços médicos da LBCMI.

\footnotetext{
${ }^{42}$ Edécio Cunha, “A insulina na desnutrição infantil” (tese de doutoramento, Faculdade de Medicina da Bahia, 1926), 57.

${ }^{43}$ Correia, Considerações sobre a atrepsia e seu tratamento, 58.

${ }^{44}$ Correia, Considerações sobre a atrepsia e seu tratamento, 43.
} 
Manoel Guimarães, em suas experiências no ano seguinte, defendeu o uso da solução glicosada após o emprego da insulina (poderia ser a ingestão de água com açúcar), para evitar acidentes de hipoglicemia. Modificou também a técnica de Edécio Cunha, no que se refere à quantidade e horário das injeções de insulina, aumentando os espaços entre uma dose e outra e ignorando sua prescrição de aplicar a injeção meia ou uma hora antes da refeição. Sete crianças foram observadas por ele, e a partir delas o pesquisador chegou à conclusão de que tanto a insulina, como o extrato tireóideo e, "mais ainda" as injeções de sangue materno eram medicações auxiliares de "alto valor" no tratamento da desnutrição infantil.

Os pesquisadores apontavam que o maior problema da desnutrição entre as crianças observadas não era a ausência de alimentos (inanição), mas alimentação inadequada. Assim, o cuidado com o regime alimentar relacionava-se diretamente ao seu aspecto nutricional. Predominava entre as crianças de 0 a 6 meses a alimentação mista ou totalmente superficial, quando a medicina já tinha decretado a obrigatoriedade de aleitamento natural até os seis meses de vida. A grande vilã da alimentação artificial eram as farinhas utilizadas na preparação dos mingaus.

Os farináceos se dividiam em compostos (ou complexos) e simples. As principais marcas das farinhas compostas utilizadas em Salvador eram Allenbury, Nestlê, Les Aliments Usuels, A. Martinet. Das farinhas simples, as mais consumidas eram a mandioca, milho, trigo e arroz. As queixas relacionadas às farinhas relacionavam-se a seus compostos e à quantidade ministrada às crianças.

Ao doutorando Nilo Costa, em 1924, Gesteira indicou o estudo da "distrofia farinacea", um distúrbio provocado pelo uso prolongado de farinhas, resultando por um lado uma subalimentação parcial pela deficiência de albumina, sais e gordura, e por outro, uma intoxicação pelo excesso de hidratos de carbono (amido). A questão colocada por ele foi a seguinte: "Porque, sendo o uso dos farináceos entre nós tão frequente, as desordens nutritivas, que deveriam provir desse uso, no entanto, rareiam?". ${ }^{45}$

Como interno, Nilo Costa teve a oportunidade de observar uma quantidade significativa de crianças que passaram pelo Hospital Santa Isabel e LBCMI e notar que as teorias de Czerny não se aplicavam em todos os aspectos ao contexto soteropolitano. Existiam os casos de distrofia farinácea, mas não apresentavam a complexidade apontada pela teoria do pediatra alemão. De modo geral, ele atribuiu a particularidade encontrada à constituição do organismo das crianças atendidas pelos serviços mencionados, ou seja, existiria no organismo dessas crianças uma tolerância maior aos farináceos. Os registros da LBCMI apontavam que de 338 crianças entre 2 e 6 meses de vida, 74\% eram alimentadas com farináceos (ele não especificou o período que esses dados cobriam). Assim, resolveu pesquisar a tolerância das crianças ao referido alimento, selecionando 10 para proceder ao exame microscópico das fezes, utilizando o método de Lugol. Esse método consistia em classificar os resíduos de amido encontrados nas dejeções a partir da reação ao Lugol (iodo $1 \mathrm{~g}$, iodeto de potássio - $2 \mathrm{~g}$, água - $50 \mathrm{~g}$ ).

\footnotetext{
45 Nilo Costa, “Distrofia farinácea” (tese de doutoramento, Faculdade de Medicina da Bahia, 1924), 43.
} 
Nilo Costa procedeu aos exames, mas disse não ter chegado a uma conclusão sobre a questão. Analisando sua tese, porém, encontramos dados e informações que podem acender uma luz ao problema. No levantamento que fez quanto ao uso dos farináceos, levantou também que o tipo de farinha utilizado pelas crianças, todas pobres, era o simples (araruta, arroz, maisena, sagu, mandioca, trigo, milho, tapioca, aveia, amidonina, cercalina - nessa ordem de consumo). Não residiria aí o fato de ele não encontrar correlação entre a teoria de Czerny e a realidade que vivia? A teoria de Czerny foi desenvolvida a partir de pesquisas com farináceos complexos e as farinhas consumidas pelas crianças que investigou estavam no rol das simples.

A pesquisa que o professor baiano Costa Pinto realizou com a farinha de mandioca brasileira pode fornecer mais elementos à reflexão. Da amostra que coletou, indicou proteínas na seguinte composição: albumina $(75 \%)$, globulina $(12 \%)$, prolamina $(37 \%)$ e glutelina (19\%). Quanto à caloria, apresentou o número de 610. Faltaram dados em relação ao amido, porém. $\mathrm{O}$ índice de albumina não seria um elemento para discutir o peso da farinha de mandioca, e talvez outras farinhas simples, na distrofia farinácea?

Dos ambulatórios da LBCMI, Cacilda Vieira dos Reis registrou os 91 casos de subalimentação infantil que subsidiaram sua tese defendida em 1927. Com esses, a doutoranda corroborou as ideias que Gesteira vinha defendendo desde 1916, de que o maior problema da subalimentação dos lactentes não estava relacionado à quantidade, mesmo entre a população pobre de Salvador, mas à qualidade dos alimentos ingeridos. ${ }^{46}$

A Bráulio Xavier da Lima Pereira Filho, Gesteira sugeriu o estudo do raquitismo. Embora limitada a pequenas manifestações, a distrofia, segundo o professor, vinha aumentado nos serviços clínicos da faculdade, sobretudo entre a população negra. As observações estavam respaldadas na concepção vigente da influência da luz na gênese do raquitismo, e como os indivíduos de maior pigmentação cutânea possuem proteção natural às irradiações ultravioletas, eles estariam mais suscetíveis a essa afecção. ${ }^{47}$ Outro fator que concorreria ao raquitismo seriam os distúrbios digestivos. ${ }^{48}$

Examinando as crianças assistidas pela LBCMI, Bráulio Xavier detectou que 25\% delas apresentavam o chamado pequeno raquitismo (o menor grau da doença), e destas $90 \%$ eram crianças pretas. Entre elas, ainda, predominava aquelas que já tinham sofrido de perturbações digestivas.

“[...] a alimentação antinatural de mingaus, de difícil digestão, predomina ainda, na classe operária, se não mesmo nas classes elevadas. De tais alimentos dimanam as alterações digestivas prolongadas que são fatores etiológicos de grande valia, pelo menos entre nós, dada a concomitância dessas perturbações com as lesões raquíticas. Acreditamos mesmo que o aleitamento artificial e a

\footnotetext{
46 Cacilda Vieira dos Reis, “Ligeira contribuição ao estudo da sub-alimentação dos lactentes" (tese de doutoramento, Faculdade de Medicina da Bahia, 1927).

${ }^{47}$ Gesteira, “Lição inaugural da clínica pediátrica médica da Bahia,” Pediatria Pratica 1, (ago.1928): 250.

${ }^{48}$ Havia várias teorias que explicavam a causa do raquitismo, mas Braulio Xavier explicava a doença como consequência desses dois fatores combinados.
} 
administração prematura de mingaus, possam ser tomados como fatores etiológicos, se bem indiretamente." 49

Temáticas relacionadas à nutrição infantil continuou sendo privilegiada no início da década seguinte. João Francisco Lages Netto, em 1930, ficou responsável por estudar a ação dos hidrocarbonos, essenciais ao metabolismo da albumina, gordura e sais - substâncias tidas como fundamentais à manutenção do peso dos lactentes. Pela sua capacidade de fornecer calorias, os hidrocarbonos seriam indispensáveis à alimentação. Sobre o mecanismo físico-químico da retenção dos hidrocarbonos apenas se sabia, segundo o doutorando, que se depositava sob a forma de glicogênio. "Como elementos participantes do fenômeno da retenção d'água, a sua ingestão em cifra insuficiente bem como perturbações no seu metabolismo intermediário conduzem a uma desnutrição". ${ }^{50}$

Para esse estudo, o melhor processo seria a determinação da curva de glicemia após a ingestão de uma alimentação contendo hidratos de carbono (H.C). O exame da curva de um indivíduo normal após uma carga hidrocarbonada mostrava que o açúcar do sangue aumentava progressivamente para atingir o máximo entre meia e uma hora depois (hiperglicemia) e em seguida descer progressivamente (hipoglicemia), retornando ao valor inicial dentre 2 e 3 horas. Assim, seria importante saber o comportamento da glicemia em doses controladas de H.C em crianças sadias, para se obter referências para detectar desvios de normalidade em entidades mórbidas. 20 lactentes foram estudados, sendo utilizado 1,3g de glicose por quilo para os testes.

Lages Netto chegou à conclusão que o tipo de alimentação dos lactentes, se natural, artificial ou mista (se a correlação básica dos componentes normais da alimentação estivesse preservada) era indiferente à glicemia; a média da "glicemia normal" dos lactentes era de $0,084 \%$, estando entre os limites estabelecidos nos estudos de outros pediatras internacionais; por fim, e mais importante, a reação glicêmica deveria ser empregada correntemente ao estudo da função hepática dos lactentes, sobretudo em idade inferior a 3 meses.

Conforme mencionado, cada tema de pesquisa cumpria um aspecto da agenda de Gesteira, em torno da cátedra da clínica pediátrica. A escolha por esses temas não era desinteressada. Conforme destaca Bourdieu, ${ }^{51}$ não há ciência sem interesse. Havia uma concorrência velada, uma corrida para não ficar aquém no cenário nacional e internacional. Assim, toda estratégia de produção do conhecimento comporta ao mesmo tempo uma dimensão científica e outra política. Essas pesquisas ganhavam importância, sobretudo, por discutirem questões relacionadas à mortalidade infantil, tema de destaque na saúde pública do Brasil de então.

\section{A Sociedade de Pediatria da Bahia em seus primeiros passos}

\footnotetext{
${ }^{49}$ Bráulio da Silva Pereira Filho, “O raquitismo na Bahia” (tese de doutoramento, Faculdade de Medicina da Bahia, 1927), 62.

${ }^{50}$ João Francisco Lages Neto, “Do metabolismo dos hidrocarbonos nos lactentes sadios da Bahia” (tese de doutoramento, Faculdade de Medicina da Bahia, 1930), 30.

${ }^{51}$ Bourdieu, “O campo científico”, 113
} 
No serviço pediátrico de Gesteira, formaram-se pediatras cujas ações ajudaram a consolidar a pediatria na Bahia. Dos internos e assistentes saíram as pesquisas publicadas nos periódicos científicos, foram compostos os membros de órgãos públicos de assistência à infância, bem como o grupo que fundou a Sociedade de Pediatria da Bahia.

Entre os internos da cátedra, alguns abraçaram a especialidade pediátrica e atuaram em espaços em Salvador ou em outras cidades. Edécio Cunha, por exemplo, foi responsável pela implantação do ensino de pediatria em Recife ${ }^{52}$ e João Francisco Lages Netto tornou-se professor de pediatria na Universidade do Brasil (RJ). Ainda que não tivessem defendido tese, os internos José Peroba e Eliéser Audiface tornaram-se profissionais assíduos do projeto duradouro da Liga Baiana Contra Mortalidade Infantil/LBCMI, juntamente com Nilo Costa. Hosannah de Oliveira e Bráulio Xavier foram os internos mais atuantes, tornaram-se assistentes e livres docentes de pediatria médica da Faculdade de Medicina da Bahia na década de 1930, apresentaram suas pesquisas em sociedades científicas e as publicaram em revistas especializadas.

A equipe de assistentes da década de 1920 - Álvaro da Franca Rocha (1888-1963), Hélio Ribeiro (1890-?), Enéas Costa e Álvaro Pontes Bahia (1888-1964) - foi essencial aos serviços médico/didáticos da cátedra de pediatria, incluindo os trabalhos desenvolvidos pela LBCMI. Álvaro Bahia, mais antigo deles, desenvolveu uma parceria com Gesteira que envolvia os estudos da pediatria clínica e os projetos de higiene infantil no Estado. E Álvaro da Franca Rocha acompanhou o mestre na fundação da SPB.

A SPB foi criada como espaço de discussão sobre as questões pertinentes à pediatria e à puericultura. Sua fundação data de 28 de maio de 1930. Gesteira fundou a agremiação científica, tornando-se seu primeiro presidente. As secretarias foram ocupadas por Álvaro de Franca Rocha e Bráulio Xavier. ${ }^{53}$ Com sede no Instituto Baptista Machado Marques, instalação da LBCMI, a SPB apresentou por objetivos:

“a) Investigar e estudar os problemas relativos à patologia e à higiene da criança, e as demais questões relacionadas com o amparo à maternidade e à infância; b) Estudar e discutir em suas sessões assuntos que lhe estejam afetos, bem como casos clínicos ou assuntos de outra natureza apresentados pelos sócios; c) Colaborar com as associações científicas ou particulares, e com os poderes públicos, na divulgação dos conhecimentos de pediatria e higiene infantil, especialmente as medidas de combate à mortalidade infantil." 54

Conforme defendem Rodriguez e Perdigueiro ${ }^{55}$, a organização de uma sociedade especializada funciona como medida de defesa e intercâmbio profissional, correspondendo ao último do que chamam de circuitos de singularização de uma área científica. No mesmo ano de sua fundação, em outubro, a SPB iniciou um periódico que divulgava as reuniões e

\footnotetext{
${ }^{52}$ Leduar de Assis Rocha, Pediatria e Puericultura em Pernambuco (Recife: ASA Pernambuco, 1987), 75-78.

53 Ao longo de sua história, a SBP teve como presidentes, entre outros, Álvaro Bahia, Braulio Xavier, Carlos Gama, Hélio Ribeiro, José Peroba e Eliezer Audiface, todos ligados aos serviços pediátricos de Gesteira.

${ }^{54}$ Estatuto da Sociedade de Pediatria da Bahia (1941), 3.

${ }^{55}$ OCAÑA Rodriguez \& E. Perdigueiro, “Ciencia y persuasión social em la medicalizasión de la infância em Espanha, siglos XIX-XX," História, Cências, Saúde-Manguinhos 2 (abr.-jun., 2006): 303-24.
} 
publicava trabalhos especializados, o Boletim da Sociedade de Pediatria da Bahia, publicados na Gazeta Médica da Bahia. Após dois anos, o boletim deu lugar à Revista de Pediatria e Puericultura.

A SPB funcionava como órgão autônomo, desvinculada à entidade nacional, mas não por opção. A SBP, fundada em 27 de julho de 1910, aprovou um estatuto que só admitia filiações efetivas de domiciliados no Distrito Federal ou municípios limítrofes. Pediatras dos estados só poderiam ser sócios correspondentes, sem direito a voto. A agremiação "nacional" foi criada por Fernandes Figueira, que foi seu presidente vitalício até 1927. Durante os anos em que o fundador da sociedade carioca esteve como presidente, a mesma funcionou nas instalações da Policlínica de Crianças da Santa Casa de Misericórdia do Rio de Janeiro, e reunia, centralmente, estudantes e pediatras que circulavam pelos serviços médicos/didáticos de Fernandes Figueira. Assim, a SBP foi bastante restrita durante suas primeiras décadas, tendo sua nacionalização ocorrido somente em 1951, com a filiação de sociedades e departamentos estaduais de Pediatria, fruto de uma ampla discussão realizada durante a primeira Jornada Brasileira de Puericultura e Pediatria (1947). ${ }^{56}$

As atas das sessões do primeiro ano da SPB denunciam que havia na capital baiana um ambiente acadêmico da especialidade pronto para acolher uma associação científica: continuidade dos encontros, pesquisas originais, debates respaldados em experiências. Além dos pediatras - Álvaro Bahia, Álvaro da Franca Rocha, Bráulio Xavier, Hildebrando Jatobá, Gesteira, Alfredo Magalhães, Hélio Ribeiro - outros médicos também apresentaram observações relacionadas à infância.

Nesses encontros, os pediatras discutiram diferentes questões. Na sessão de 31 de outubro de 1935, Bráulio Xavier e José Peroba, por exemplo, propuseram que a SPB e a LBCMI patrocinassem uma campanha contra a tuberculose infantil, sendo que a última criaria um departamento exclusivamente destinado a esse fim, com patrimônio financeiro próprio. Gesteira, enquanto presidente da associação, nomeou uma comissão composta pelos proponentes, mais Álvaro Bahia e Carlos da Gama para discutirem a questão. Franca Rocha sugeriu que a Sociedade se reunisse extraordinariamente em duas sessões anuais para estudar a atualidade pediátrica nos diferentes centros culturais.

Na sessão de 28 de novembro de 1935, seguinte à proposição, a comissão já apresentou o resultado de estudo desenvolvido a respeito do combate à tuberculose infantil. O plano apresentado dividia-se em duas partes: terapêutica e profilaxia. A primeira parte consistia na fundação de um ambulatório especializado, dotado de arsenal terapêutico, tuberculina para exames cutâneos, filmes radiográficos e aparelho de pneumotórax artificial. Todas as instalações, incluindo os registros clínicos, deveriam ser separados dos demais serviços da LBCMI. A profilaxia consistia no auxílio do serviço já existente do B.C.G., campanhas pela mídia impressa e radiofônica, além de conferências públicas divulgando os meios de prevenção e tratamento da doença. Na mesma sessão, discutiu-se também a criação de escola para excepcionais, agenda da reforma do ensino em curso.

\footnotetext{
${ }^{56}$ Glauco Carneiro, Um compromisso com a esperança: história da Sociedade Brasileira de Pediatria, 1910-2000 (Rio de Janeiro: Expressão e Cultura, 2000), 254-256.
} 
Sociedades científicas, com seu respectivo periódico, cumprem um papel de consolidar os princípios da ciência oficial, na medida em que possibilita que as produções sejam divulgadas, debatidas e publicizadas. Além disso, torna-se um meio importantíssimo de acumulação de capital científico para os pesquisadores. Quase a totalidade das produções de Álvaro Bahia, por exemplo, foram publicadas na revista da SPB.

Através desse espaço é possível pensar a respeito do funcionamento da distribuição do capital científico, o que, na perspectiva de Bourdieu é o que define a estrutura de um campo num dado momento. São nas sessões de uma sociedade científica que os atos de conhecimento e reconhecimento ocorrem pelo conjunto de "pares-concorrentes" componentes do campo, ações importantes ao acúmulo de capital científico. Em seus anos iniciais, a SPB funcionou em torno da produção da cátedra de Gesteira, embora outros profissionais, pediatras ou não, pudessem compartilhar suas pesquisas. O mesmo se pode afirmar em relação à junta administrativa da sociedade. Glauco Carneiro apontou esse último aspecto em relação à Sociedade Brasileira de Pediatra, afirmando que havia "a tradição" de somente "discípulos" de Fernandes Figueira, invariavelmente ligados à Policlínica de Crianças e depois ao Hospital Artur Bernardes, ocuparem a direção da entidade entre 1910 e 1928, até o falecimento de seu fundador e diretor vitalício. ${ }^{57}$

Os lugares que os agentes ocupam nesse espaço estão condicionados, invariavelmente, ao crédito que detêm. O direcionamento das questões discutidas, assim como a "última palavra" nos comentários dos debatedores foram predominantemente de Gesteira. Não se quer dizer com isso que havia um cerceamento por parte do diretor, tratava-se, certamente, de estratégia para a conservação da estrutura.

"Pode-se genericamente verificar que quanto mais as pessoas ocupam uma posição favorecida na estrutura, mais elas tendem a conservar ao mesmo tempo a estrutura e sua posição, no limite, no entanto, de suas disposições (isto é, de sua trajetória social, de sua origem social) que são mais ou menos apropriadas à sua posição." 58

Hosannah de Oliveira e João Francisco Lages Netto, mesmo tendo sido internos e parte da equipe médico/didática de Gesteira, não atuaram na SPB. Oliveira participou no primeiro ano e somente como comentador, sem apresentar comunicações, embora fosse membro associado. Em 1932, os dois estavam envolvidos na recuperação da Sociedade de Medicina da Bahia (SMB), fundada em junho de 1908, compondo o conselho editorial de sua revista, a Bahia Médica. ${ }^{59}$ Em meados da década de 1930, Lages Netto mudou-se para o Rio de Janeiro e Hosannah de Oliveira continuou na cidade, assumindo a $2^{2}$ vice-presidência da SMB para o biênio 1935-1936. No ato de posse, o diretor da SMB se pronunciou a respeito do crescimento de agremiações no período, defendendo que as associações médicas por especialidades enfraqueciam a medicina enquanto grupo científico e político. Hosannah de Oliveira compartilhava essa opinião? Não se sabe, mas o fato é que em sua trajetória

\footnotetext{
${ }^{57}$ Carneiro, História da Sociedade Brasileira de Pediatria, 143-146.

${ }^{58}$ Bourdieu, Os usos da ciência, 29.

${ }^{59}$ As publicações locais de Hosannah de Oliveira eram feitas na Revista Bahia Médica. Posteriormente, ele se tornou proprietário e principal editor da revista.
} 
profissional não atuou em sociedades de pediatria, local ou nacionalmente, como era comum entre os grandes pediatras baianos de sua geração. ${ }^{60}$

Para além da entidade científica que Hosannah de Oliveira tenha escolhido se associar, seu distanciamento dos espaços dominados pelo grupo de Gesteira chama atenção. ${ }^{61}$ Em 1934, iniciou uma campanha para reerguer o Instituto de Proteção e Assistência e à Infância da Bahia, quando a Liga Baiana Contra Mortalidade Infantil já tinha se estabelecido como espaço médico/didático da faculdade de medicina. Atuou como pediatra e esteve à frente das questões políticas do IPAI até 1938. Em 1936, engajou-se politicamente em ações que visavam a construção de um hospital para a faculdade de medicina, integrando a diretoria do Núcleo Acadêmico pró-Hospital das Clínicas.

As evidências indicam que Hosannah de Oliveira pretendia trilhar caminho autônomo desde o início de seu doutoramento. No ano em que defendeu sua tese, foi nomeado para uma comissão incumbida do serviço de verificação de óbitos dos distritos de Pirajá e Paripe, recolhendo dados sobre mortalidade infantil no estado por força da solicitação da Liga das Nações. E passado pouco mais de um ano da execução das atividades dessa comissão, lançou-se ao concurso, bem sucedido, para livre docente em Clínica Médica Pediátrica e Higiene Infantil da Faculdade de Medicina da Bahia, em 1930. Ao contrário dos outros internos da cátedra de Gesteira que fizeram carreira pediátrica em Salvador, Hosannah de Oliveira não atuou nos espaços criados pelo professor.

A trajetória de Hosannah de Oliveira pode ser pensada a partir do que Bourdieu classificou como "estratégias de subversão" 62 . Como novato, talvez o recém-formado não quisesse que os lucros de suas pesquisas, fruto de um investimento acadêmico, se tornasse monopólio da legitimidade científica de Martagão Gesteira. Na luta do campo da pediatria clínica, em que, como todo campo, não havia uma distribuição equitativa do capital acumulado, Oliveira deve ter feito um cálculo e preferiu arriscar uma trajetória científica autônoma, onde, certamente, alcançaria um reconhecimento maior.

A primeira sessão da SPB do ano de 1937 ocorreu sem seu presidente fundador, pois Martagão Gesteira já tinha se transferido para o Rio de Janeiro para assumir a direção do Instituto Nacional de Puericultura e reger a Cátedra Puericultura e Clínica da Primeira Infância - criada com o desdobramento da Clínica Pediátrica Médica e Higiene Infantil - na Universidade do Brasil. A transferência de Gesteira para a capital propõe uma reflexão sobre duas questões importantes. A primeira, relativa à construção de uma nova disciplina pediátrica focada na puericultura e primeira infância, resgata uma questão proposta por Timothy Lenoir sobre "programa de pesquisa" que cria disciplina acadêmica. ${ }^{63} \mathrm{E}$ a segunda,

\footnotetext{
${ }^{60}$ Ao longo de sua carreira, Hosannah de Oliveira foi presidente da Associação Baiana de Medicina e vicepresidente fundador da Associação Brasileira de Medicina, Provedor da Santa Casa de Misericórdia da Bahia, Diretor da Faculdade de Medicina da Bahia, Membro da Academia de Medicina da Bahia e Diretor e proprietário da Revista Médica da Bahia (E. M. Baleeiro \&, A. L. L. O. Baleeiro, org., Centenário do Dr. Hosannah de Oliveira (Salvador: Secretaria da Cultura e Turismo, 2002).

${ }^{61}$ Entre 1926 e 1927 tinha sido Interno da Clínica Pediátrica Médica e Higiene Infantil e Auxiliar Acadêmico da Liga Baiana contra a Mortalidade Infantil.

62 Bourdieu, "O campo científico," 123.

${ }^{63}$ Timothy Lenoir, "A disciplina da natureza e a natureza da disciplina," in Instituindo a Ciência: a produção cultural das disciplinas científicas (Rio Grande do Sul: Unisinos, 2004): 62-98.
} 
à posição que Gesteira alcançou no campo por causa do capital científico acumulado que o levou a assumir a cátedra na universidade da capital federal.

A partir da década de 1920, como visto anteriormente, os estudos da pediatria referentes à primeira infância, entendida como processo de adaptação à vida, ganharam protagonismo. Nesse contexto, a higiene infantil tornou-se central entre os assuntos pediátricos, entendendo-se que a prevenção era essencial em um público cujas resistências orgânicas seriam naturalmente precárias. Desse modo, a Puericultura foi ocupando espaços cada vez mais ampliados tanto em ambientes científicos como entre o poder público, trazendo à tona questões relativas à maternidade, à morbidade e mortalidade infantis, educação sanitária das genitoras, à cultura física da criança, aos regimes alimentares da primeira infância e aos princípios do eugenismo. Desse contexto, surgiu uma disciplina específica para discutir essas questões 'Puericultura e Clínica da Primeira Infância'. A segunda reflexão diz respeito ao profissional convidado a ministrar a disciplina recémcriada: Martagão Gesteira. Esse convite foi decorrência do capital científico (e político) que o pediatra baiano construiu, abordado ao longo deste artigo.

Quem sucedeu Gesteira na presidência da SPB, na LBCMI e, interinamente, na cátedra da Faculdade de Medicina da Bahia foi seu assistente, e "braço direito", Álvaro Pontes Bahia. Capital científico, porém, não é algo que se transmita, já que está relacionado à pessoa, envolvendo atitudes e carisma. Para ocupar o lugar deixado por Gesteira, ele teria que ter acumulado maior capital simbólico e, mais especificamente, científico. O percurso de Pontes Bahia ficou "restrito" ao desenvolvimento dos projetos da Liga, que sob sua presidência concretizou o objetivo de construção de um hospital para crianças especializado em primeira infância, que recebeu o nome de Hospital Martagão Gesteira.

Além de agremiação de interesses científicos, a sociedade pode ser pensada também como 'escola', na medida em que as questões suscitadas e seus argumentos acabavam sendo compartilhados coletivamente, contribuindo para a formação de um perfil profissional. Assim, a SPB foi um espaço de integração e fortalecimento do campo da ciência médica especializada na infância.

\section{Considerações finais}

Percorrendo o cenário atual soteropolitano no que diz respeito às instituições pediátricas especializadas encontramos somente dois nomes: Hosannah de Oliveira (Centro Pediátrico do Hospital das Clínicas-UFBA) e Martagão Gesteira (Hospital Especializado em Pediatria - filantrópico). Ao Hospital Martagão Gesteira, vincula-se a Liga Álvaro Bahia Contra a Mortalidade Infantil, fundação mantenedora do referido hospital. As histórias dessas três instituições têm origem no período tratado neste artigo e esses nomes são mais que homenagens: Martagão Gesteira, Hosannah de Oliveira e Álvaro Bahia foram os pediatras cujas ações médico-científicas e políticas tornaram possível a consolidação desses espaços de assistência à infância. Suas atuações, por sua vez, estão relacionadas aos trabalhos desenvolvidos por Martagão Gesteira em torno da cadeira de Clínica Pediátrica Médica e Higiene Infantil da Faculdade de Medicina da Bahia. Álvaro Bahia e Hosanah de Oliveira foram assistentes e livre docentes da cátedra, sendo que o último também foi interno do serviço clínico do mesmo professor. 
Essas trajetórias, e de todos os mencionados aqui, colocam a atuação de Martagão Gesteira à frente da Clínica Pediátrica e Higiene Infantil num patamar único desde a criação da cátedra no último quartel do oitocentos. De fato, somente a partir dele egressos da Faculdade de Medicina da Bahia tornaram-se propriamente pediatras. Para além do encantamento que o professor provocava - pela atenção especial dada à semiologia infantil -, a postura científica, em sua conexão social e política, foi fundamental para que os estudantes passassem a se interessar academicamente pela pediatria.

Aliado a isso, o contexto foi marcado por uma disputa em que a cátedra de clínica pediátrica impôs sua hegemonia, pois possuía em seu programa disciplinar e de pesquisa as questões da higiene. No decorrer da década de 1920, a higiene foi ocupando um espaço cada vez maior na dimensão social da medicina, resgatando fortemente o ramo preventivo da medicina infantil, a Puericultura. Martagão Gesteira engajou-se de tal maneira que figurou entre os grandes nomes da pediatria nacional, transferindo-se para o Rio de Janeiro em 1937 para assumir uma cátedra que tratava das questões as quais tinha se tornado referência. 